\title{
Uso de sangue de frangos e de bovinos na alimentação de Argas (Persicargas) miniatus (Koch, 1848) (Acari, Argasidae), através de membrana de silicone*
}

\author{
The use of Chicken and Cattle blood to feed Argas (Persicargas) \\ miniatus (Koch, 1848) (Acari, Argasidae), through silicone membrane
}

Adivaldo Henrique da Fonseca, ${ }^{\star \star}$ Ary Elias Aboud Dutra, ${ }^{\star \star \star}$ Isabelle Garcia Pina***

\begin{abstract}
Resumo
O sangue total desfibrinado ou adicionado de citrato de sódio de frangos e de bovinos foi utilizado para alimentar o carrapato Argas (Persicargas) miniatus, através de membranas de silicone, as quais tinham a espessura de $0,056 \mathrm{~mm}$ fagoestimulante consistiu de prévio pincelamento de aproximadamente $0,06 \mathrm{ml}$ do líquido resultante da depenagem das frangos de abatedouro comercial, contendo fragmentos de pele e penas. O sangue das aves foi $100 \%$ eficaz na alimentação de ninfas e adultos de $A$. (P.) miniatus, sendo que a substituição pelo sangue bovino apresentou resultados acima do obtido para o grupo controle, alimentado diretamente sobre as aves. Fêmeas alimentadas com sangue de frangos ou de bovino através da membrana, ou diretamente nas aves, fizeram postura 6 a 9 dias após o repasto sangüíneo. A muda dos estádios de ninfas ocorreu entre 7 a 10 dias depois da alimentação, independentemente da fonte de sangue. Os resultados obtidos indicam ser possivel otimizar a manutenção de colônias de $A$. (P.) miniatus em laboratório, através da alimentação artificial com uso de sangue de aves ou bovino e membrana de silicone. A membrana demonstrou ser de fácil manipulação, baixo custo e reutilizável.
\end{abstract}

Palavras-chave: alimentação artificial; membrana de silicone; Argas(Persicargas) miniatus, aves; bovinos.

\section{Introdução}

O carrapato Argas (P.) miniatus (Koch, 1848), segundo Kohls et al. (1970), é uma espécie de importância econômica para as Américas, relacionada com anemia causada pela espoliação direta das aves parasitadas, diminuição da produtividade, transmissão da Borrelia anserina e outros patógenos. $O$ argasídeo apresenta como característica biológica o estádio larval que permanece sobre o hospedeiro pelo período de 3 a 7 dias para se alimentar, ninfas realizando de 3 a 5 mudas e os estádios de ninfas e adultos se alimentando entre 10 a 40 minutos, preferentemente à noite, além de possuírem dimorfismo sexual pouco evidente.

O uso de técnicas de alimentação artificial apresenta vantagens sobre as técnicas tradicionais que empregam hospedeiros naturais. Ogston e Yanovski (1982) desenvolveram método eficaz para alimentação de artrópodes hematófagos, e Davis et al. (1983) descreveram o preparo de membranas reforçadas à base de silicone e verificaram que o rendimento da postura de fêmeas de Culicoides mississippiensis foi mais eficiente quando alimentadas através de membrana de silicone, tendo como fonte alimentar sangue bovino desfibrinado e citratado, quando comparados com o de fêmeas do artrópode, alimentadas em humanos.

Hindle e Duncan (1925), pesquisando a possibilidade de manutenção e transmissão de patógenos pelo Argus persicus, conseguiram alimentá-los com soro eqüino através de membranas feitas com diafragma e parede abdominal de cobaios e coelhos. Burgdorfer e Pickens (1954) desenvolveram uma técnica para alimentação de argasídeos e transmissão de patógenos, utilizando membranas da câmara de ar de ovos embrionados de galinha. Tarshis (1958) usou 11 diferentes tipos de membrana de origem animal para alimentar Ornithodorus savigny com

\footnotetext{
*Trabalho realizado sob os auspícios do CNPq

**Professor Titular, Departamento de Epidemiologia e Saúde Pública da Universidade Federal Rural do Rio de Janeiro, Km 47 da antiga Rodovia Rio -São Paulo, Cx. Postal 74548 Seropédica, RJ. e-mail adivaldo@ufri.br

***Mestrandos em Medicina Veterinária - Parasitologia Veterinária da UFRRJ.
} 
sangue humano citratado. Galun e Kindler (1965), trabaIhando com $O$. tholozani alimentados artificialmente através de membrana parafilm com sangue humano, estudaram diferentes substâncias fagoestimulantes e repelentes, e Uchikawa (1976) trabalhou com sistema de alimentação artifical para estudo da transmissão de viroseses por Argas. japonicus.

Cinco espécies do gênero Ornithodorus foram alimentadas por Butler et al. (1984), através de membrana de silicone com sangue citratado bovino, adicionados de antibióticos, sangue desfibrinado suíno, papa de eritrócitos e extrato de baço suíno, verificando a possibilidade de transmissão in vitro do vírus da peste suína africana. No mesmo experimento, os autores relacionaram as vantagens do uso da membrana de silicone. Moura et al. (1997) e Rocha et al. (1997) obtiveram sucesso na alimentação respectivamente de Amblyomma cajennense e Rhodnius pictipes, através de membrana de silicone.

O objetivo do presente trabalho foi usar a membrana de silicone como técnica alternativa, para manutenção de colônias de $A$. (P.) miniatus, utilizando sangue de aves e de bovinos.

\section{Material e métodos}

Foram utilizados espécimens de $A$. (P.) miniatus, provenientes de criações rústicas de galinhas, Gallus gallus domesticus, do Município de Santo Antônio do Pinhal, Estado de São Paulo. Ínstares de diferentes fases evolutivas eram mantidos na forma de colônia, em frascos de vidro cilíndrico, com capacidade de $1.000 \mathrm{ml}$, vedados com tule de náilon e contendo em seu interior pedaços de madeira com casca, para abrigo. Os argasídeos foram mantidos em câmara climatizada à temperatura de $28 \pm 0,5^{\circ} \mathrm{C}$, umidade relativa de $75 \pm 5 \%$ e 12 horas de fotoperíodo. 0 experimento foi conduzido no Laboratório de Doenças Parasitárias do Convênio Universidade Federal Rural do Rio de Janeiro e Embrapa, Km 47 da antiga Rodovia Rio São Paulo, Seropédica, Rio de Janeiro.

Para manutenção da colônia, ninfas e adultos eram retirados aleatoriamente e mantidos em recipientes de plásticos com altura de $4,5 \mathrm{~cm}$, extremidade superior com diâmetro de $5,0 \mathrm{~cm}$ e base com diâmetro de $4,0 \mathrm{~cm}$, tendo a tampa de rosca substituída por tecido tipo tule. Os recipientes com 10 exemplares eram colocados sobre a face externa das coxas de frangos e fixados com fita gomada, de forma que a abertura, coberta por tule de náilon, ficasse em contato com a pele pelo período de 60 minutos.

O sangue de frangos de granja foi coletado assepticamente por punção cardíaca, e o de bovinos, por punção da veia jugular. Para ambos os hospedeiros, usou-se a concentração de 1 parte de citrato dextrosado para 6 partes de sangue. Para desfibrinação foram utilizadas pérolas de vidro. Em todos os casos o sangue foi mantido no máximo por 7 dias sob refrigeração.
As membranas de silicone emoregadas, tinham a espessura de $0,056 \mathrm{~mm}$ e foram preparadas conforme descrição de Davis et al. (1983). O fagoestimulante utilizado sobre as membranas consistiu no pincelamento de aproximadamente $0,06 \mathrm{ml}$ com o líquido resultante da depenagem das aves no abatedouro comercial, contendo fragmentos de pele e penas, e secas ao ambiente. As mesmas membranas foram usadas sucessivas vezes, após lavagem com água e detergente neutro.

O sangue era retirado com antecedência do refrigerador e deixado à temperatura ambiente, até estabilizar com a do meio, e envazado em recipientes de plástico, com capacidade para $3,5 \mathrm{~cm}^{3}$ cada, sendo recobertos com a membrana de silicone, com a face rugosa voltada para o meio externo e a face lisa voltada para os recipientes com 0 sangue. Os frascos contendo sangue eram colocados sobre uma placa de bronze com dimensões $20 \mathrm{~cm} \times 15 \mathrm{~cm} \times$ $2,0 \mathrm{~cm}$, com serpentina em seu interior, por onde circulava água previamente aquecida, ${ }^{1}$ e mantida dentro da câmara climatizada, com temperatura de $28 \pm 1^{\circ} \mathrm{C}$ e umidade relativa de $75 \pm 5 \%$. A placa tinha como proteção uma folha dupla de papel-toalha, a qual era periodicamente umidecida. Os argasídeos eram retirados aleatoriamente da colônia em grupos de 10 e mantidos sobre o aparato de alimentação pelo período de 60 minutos. Os carrapatos do grupo controle eram alimentados em lotes de 10, na face externa da coxa de frangos de granja, pelo período de 60 minutos.

\section{Resultados e discussão}

O sangue de frangos, oferecido através da membrana de silicone com fagoestimulante, foi $100 \%$ eficaz na alimentação de ninfas e adultos de $A(P$.$) miniatus. A substitui-$ ção do sangue de aves pelo sangue bovino, mantendo o uso de fagoestimulantes, apresentou resultados acima do obtido para o grupo controle, alimentado diretamente sobre aves. Fêmeas alimentadas com sangue de frangos ou de bovino, através da membrana de silicone e diretamente nas aves, fizeram postura 6 a 9 dias depois do repasto sangüíneo. A muda dos estádios de ninfas ocorreu entre 7 e 10 dias após a alimentação, independentemente da fonte de sangue. Os diferentes tipos de fonte de sangue e eficácia de alimentação através da membrana de silicone e grupo controle estão representados na Tabela 1.

O sangue de bovinos foi escolhido como fonte alternativa, devido à facilidade de sua obtenção a nível de matadouro e por possibilitar o estudo comparativo para transmissão de patógenos. O tempo utilizado para alimentação artificial foi de 60 minutos, sendo que a maioria alimentou-se nos primeiros 15 minutos. Resultados semelhantes foram observados por Tarshis (1958) e Osborne e Mellor (1985) que

\footnotetext{
1 Equipamento de aquecimenteo de circulação de água Model K20 American Pharmaseal Company.
} 
Tabela 1: Efeito do sangue de diferentes hospedeiros, adicionados ou não de fagoestimulante na alimentação de $\operatorname{Argas}(P$.) miniatus, através de membrna de silico-ne em temperatura de $39,5 \pm 0,5^{\circ} \mathrm{C}$

\begin{tabular}{|c|c|c|c|c|}
\hline Origem do sangue & Fagoestimulante* & $\begin{array}{c}\text { Almentados } \\
(n)\end{array}$ & $\begin{array}{c}\text { Não-alimentados } \\
(\mathrm{n})\end{array}$ & $\begin{array}{l}\% \text { de } \\
\text { alimentados }\end{array}$ \\
\hline Desfibrinado de bovino & - & 20 & 180 & 10 \\
\hline Citratado de bovino & - & 109 & 201 & 35 \\
\hline Citratado de bovino & $\begin{array}{l}\text { Lavado de } \\
\text { matadouro }\end{array}$ & 81 & 19 & 81 \\
\hline Desfibrinado de frango & $\cdot$ & 35 & 65 & 35 \\
\hline Citratado de frango & - & 60 & 40 & 60 \\
\hline Citratado de frango & $\begin{array}{l}\text { Lavado de } \\
\text { matadouro }\end{array}$ & 150 & 0 & 100 \\
\hline $\begin{array}{l}\text { Controle - alimentados } \\
\text { em frangos }\end{array}$ & - & 175 & 55 & 76 \\
\hline TOTAL & & 630 & 560 & \\
\hline
\end{tabular}

* Aproximadamente $0,06 \mathrm{ml}$ do líquido resultante da depenagem das aves no abatedouro comercial, contendo fragmentos de pele e penas.

trabalharam com alimentação artificial de Ornithodoros savignyi e 0 . moubata, respectivamente. Resultados variáveis sobre a eficácia de sangue de mamíferos para alimentar argasídeos têm sido reportados. Tawfik e Guirgis (1969) obtiveram resultados satisfatórios, embora a ovipostura tenha sido significativamente menor quando alimentaram Argas (Persicargas) arboreus com sangue de coelhos, quando comparado com sangue de aves.

Osborne e Mellor (1985), estudando a manutenção de $O$. moubata alimentados através de membranas naturais e artificiais, com diferentes fontes de alimentos, concluíram que os melhores resultados foram obtidos com membrana de silicone e sangue de camundongo. Wirtz e Barthold (1986), trabalhando com O. moubata e membrana de silicone, verificaram que o sangue desfibrinado levou a índices inferiores ao sangue citratado e, ainda, que a adição de ATP aumentava o número de carrapatos alimentados. Hokama et al.(1987), trabalhando com membranas de parafilme, testaram vários fatores que influenciavam positivamente a alimentação de Ornithodoros coriaceus, e Schwan et al. (1991), trabalhando com O. moubata alimentados através de membranas de parafilme, testaram a eficácia de diferentes fontes de alimentos, sendo os meIhores índices encontrados com sangue bovino.

As temperaturas utilizadas no presente trabalho para alimentação artificial variaram entre $35,5^{\circ} \mathrm{C}$ e $41.5^{\circ} \mathrm{C}$ para a fonte de calor (Tabela 2), ficando próxima aos achados de
Galun e Kindler (1965), Mango e Galun (1977), Butler et al. (1984), que trabaIharam com argasídeos. Tawfik e Guirgis (1969), ao trabalharem com membrana artificial para alimentação de $A$. (P.) arboreus descreveram que a temperatura da membrana deve ser superior a $38^{\circ} \mathrm{C}$ e inferior a $42^{\circ} \mathrm{C}$, Hokama et al. (1987), trabalhando com O. coriaceus, usaram a temperatura da superfície entre $36^{\circ} \mathrm{C}$ e $38^{\circ} \mathrm{C}$, e Osborne e Mellor (1985) usaram a temperatura da água como fonte de calor a $42^{\circ} \mathrm{C}$, com variacões de $1^{\circ} \mathrm{C}$, para alimentar artificialmente $O$. moubata.

A influência dos fatores que afetam o melhor rendimento na alimentação artificial foi determinada pelos trabalhos de Galum et al. (1967), Galum e Kindler (1965), Friend e Smith (1977), que resaltaram a eficácia dos estímulos tátil, visual, olfatório, da umidade, da tensão de $\mathrm{Co}_{2}$, e da presença dos fosfatos. As diferenças na fonte alimentar, como no tipo de anticoagulante utilizado e fagoestimulantes, têm sido apontadas por vários autores, como Galun (1967), Schwan et al. (1991), Waladde et al. (1993), por influenciar a alimentação, a mortalidade e o rendimento biológico em vários artrópodes hematófagos.

Os resultados obtidos indicam ser possível otimizar a manutenção de colônias de $A$. (P.) miniatus em laboratório através da alimentação artificial com uso de sangue bovino e membrana de silicone. A membrana demonstrou ser de fácil manipulação, baixo custo e reutilizável. Os artrópodes alimentaram-se de forma similar ao observado durante a alimentação nos hospedeiros vivos.

Tabela 2: Efeito da temperatura sobre a alimentação de $A$. (P.) miniatus, através de membrana de silicone e sangue citratado de frango, com adição de fagoestimulante*.

\begin{tabular}{cccc} 
Temperatura ${ }^{\circ} \mathrm{C}$ & Alimentados & Não-alimentados & \% \\
\hline 35,5 & 42 & 58 & 48 \\
37,5 & 72 & 48 & 60 \\
39,5 & 118 & 2 & 98 \\
41,5 & 30 & 90 & 25 \\
\hline
\end{tabular}

* Aproximadamente $0,06 \mathrm{ml}$ do líquido resultante da depenagem das aves no abatedouro comercial, contendo fragmentos de pele e penas.

\begin{abstract}
$\operatorname{Argas}(P$.$) miniatusticks were allowed to feed on chicken and bovine citratated or desfibrinated whole blood. The silicone$ membranes used had a thickness of $0,056 \mathrm{~mm}$ and were painted with a fagostimulant of, $0,06 \mathrm{ml}$ liquid washings from the plucking of chickens from a commercial slaughterhouse, containing skin and feather fragments. The chicken blood was $100 \%$ eficient in the feeding of nymphs and adults of the ticks. Substitution of chicken by bovine blood, gave a higher result than in the control group, wich was fed directly on chickens. Female ticks, fed with chicken or bovine blood through
\end{abstract}


the membrane, or directly on chickens, laid their eggs 6 to 9 days after feeding to repletion. Mounting of nymphs to adult ticks, took place 7 to 10 days after the feeding, independently of the origin of blood. The results indicated that it should be possible greatly facilitate the maintenance of colonies of $A$. (P.) miniatus in laboratory by their artificial feeding on chicken or bovine blood through a silicone membrane. The membrane was shouwn to be convenient, low cost and reusable.

Keywords: Artificial feeding; silicone membrane; Argas (P.) miniatus; chicken; cattle.

\section{Referências bibliográficas}

BURGDORFER, W., PICKENS, E. G. A technique employing embryonated chicken eggs for the infection of argasid ticks with Coxiella burnetii, Bacterium tularense, Leptospira icterohaemorrhagiae, and western equine encephalitis virus. J. Inf. Dis. v. 94, p. 84-89, 1954.

BUTLER, J. F., Hess, W. R., ENDRIS, R. G., HOLCHER, K. H. In vitro feeding of Ornithodoros ticks for rearing and assessment of diseases transmission, p. 1075-1081. In D.A. Griffiths and C.E. Bowman (ed.), Acarology VI, Vol. 2. Ellis Horwood, West Sussex, England. 1984.

DAVIS, E. L., BUTLER, J. F., ROBERTS, R. H., REINERT, J. F., KLEINE, D. L. aboratory blood feeding of Culicoides mississippensis (Diptera: Ceratopogonidae) through a reinforced membrane J. Med. Entomol, v. 20, p. 177-182, 1983.

FRIEND, W. G., SMITH, J. J. B. Factores affecting feeding by bloodsucking insects. Ann. Rev. Entomol,. v., 22, p. 309331, 1977.

GALUN, R. Feeding stimuli and artificial feeding. Bull. WId. Hlth. Org., v. 36, p. 590-593, 1967.

GALUN, R, KINDLER, S. H. Glutathione as an inducer of feeding in ticks. Science, v. 147, p. 166-167, 1965.

HINDLE, E., DUNCAN, J. F. The viability of bacteria in Argas persicus. Parasitol, v. 17, p. 434-446, 1925.

HOKAMA, Y., LANE, R. S., HOWARTH, J. A. Maintenance of adult and nymphal Ornithodoros coriaceus (Acari: Argasidae) by artificial feeding through a parafilm membrane. J. Med. Entomol., v. 24, p. 319-323, 1987.

KOHLS, G. M., HOOGSTRAAL, H., CLIFFORD, C. M., KAISER, M. N. The subgenus Persicargas (Ixodoidea, Argasidae) Argas. 9. Redescription and new world records of $A$. (P.) radiatus (Railliet), $A$. (P.) sanchesi (Dugés) and $A$. (P.) miniatus (Koch), new wold tick misidentified as $A$. (P.) persicus. Ann Entomol Soc Am, v. 63, p. 590-606, 1970.

MANGO, C. K. A., GALUN, R. Ornithodoros moubata: breeding in vitro. Exp Parasitol, v. 42, p. 282-288, 1977.

MOURA, S. T., FONSECA, A. H., FERNANDES, C. G. N., BUTLER, J. F. Artificial Feeding of Amblyomma cajennense
(Acari: Ixodidae) through silicone membrana. Mem Inst Oswaldo Cruz v. 92, p. 545-548, 1997.

OGSTON, C. W., YANOVSKI, A. D. An improved artificial feeder for bloodsucking insects. J. Med. Entomol. v. 19, p. 42-44, 1982.

Osborne, R., MELLOR, P. S. Use a silicone membrane feeding techinique in the laboratory maintenance of a colony of Ornithodoros moubata. Trop. Anim. Health. Prod., v. 17, p. 31-38, 1985.

ROCHA, D. S., FONSECA, A. H., COSTA, F. A., JURBERG, J., GALVAO, C. Desenvolvimento de Rhodnius pictpes Stal, 1872 alimentados através de membrana de silicone e em camundongos (Hemiptera, Reduviidae, Triatominae). Mem. Inst. Oswaldo Cruz, v. 92, p. 553558, 1997.

SCHWAN, E. V., VUTTON, D., SHIELDS, K. J. B., TOWNSON, S. Artificial feeding and successful reproduction in Ornithodoros moubata moubata (Murray, 1877) (Acarina: Argasidae) Exp. App. Acarology., v. 13, p. 107-115, 1991.

TARSHIS, I. B. A preliminary study on feeding Ornothodorus savigny (Audouin) on human blood through animal-derived membranes (Acarina: Argasidae). Ann. Entomol. Soc. Am., v. 51, p. 294-299, 1958.

TAWFIK, M. S., GUIRGIS, S. S. Biochemical and phisiological studies of certain ticks (Ixodoidea). Experimental feeding of Argas (Persicargas) arboreus Kaiser, Hoogstral and Kols (Argasidae) through membranes. J. Med. Entomol., v. 6, p. 191-195, 1969.

UCHIKAWA, K. A membrane feeding method for Argas japonicus (Ixodoidea: Argasidae) and applications of this method for culturing the tick and for oral infecting of japanese encephalitis virus. Jpn. J. Sanit. Zool., v. 27, p. 207-216, 1976.

WALADDE, S. M., OCHIENG, S. A., GICHUHI, P. M. Artificial membrane feeding of the ixodid tick Rhipicephalus appendiculatus to repletion. Experimental and Applied Acarology, 11, p. 297-306, 1991.

WIRTZ, H. P., BARTHOLD, E. Simplified membrane feeding of Ornithodoros moubata (Acarina: Argasidae) and quantitative transmisson of microfilariae of Dipetalonema viteae (Nematoda: Filarioidea) to the ticks. Z. Angel. Zool., v. 73, p. 1-12, 1986. 